\title{
The Factors Impede Teachers' Effective Use of Audio Visual Materials to Teach English Speaking Skills: ABBA PASCAL Girls' School in Focus, Wolaita Zone, Southern Ethiopia \\ DOI: https://doi.org/10.47175/rielsj.v1i3.157
}

\author{
${ }^{1}$ Department of English \\ Language and Literature, Arba \\ Minch University, Ethiopia, \\ East Africa \\ ${ }^{2}$ Department of Rural \\ Development and Agricultural \\ Extension College of \\ Agriculture, Wolaita Sodo \\ University, SNNPR, Ethiopia., \\ East Africa \\ "mspathy9@gmail.com
}

| Amanuel Yonas ${ }^{1}$ | Senapathy. $\mathbf{M}^{2,{ }^{*}}$ |

\begin{abstract}
The purpose of this study was to explore factors impede teachers' effective use of AVMs to teach ESS at Abba Pascal Girls' School. The subjects used were 2 English teachers of grades 5, 6, 7 \& 8 and sampled students. The grades had 2 sections that encompassed 50 students each. Convenience \& systematic sampling techniques were employed to select the school \& 32 informants among the population of 400 . To get the exact number of the participants which are 4 of each section, the researchers divided the population's number of the sections into the numbers of each student's representation accordingly: $50 \div 4=$ 12.5. Thus, every $N^{\text {th }}$ participant was selected systematically according to their attendance lists. Therefore, 4 informants from each section were taken in the intention of the researchers. Both the teachers were directly taken as participants due to the manageable number of entire population. Then, the researchers employed mixed research approach after collecting data through questionnaire, interview \& classroom observation. Quantitative data were analyzed in percentages; while qualitative were thematically organized \& categorized in a statement form. Conclusion \& recommendations were forwarded based on the findings. The findings are learning ESS using AVMs benefit teachers \& students. Conversely, the challenges drawback teachers' effective use of AVMs were underpinned in categories of, the challenges related to classroom, gadgets, teachers \& students. Therefore, stakeholders of the school should facilitate technical training sessions for teachers \& consider the class size. Finally, the windows of the classrooms should be painted with non-translucent paints.

KEYWORDS

Abba Pascal Girls' School; Audiovisual materials; English Speaking skills; English teachers; Girls Students.
\end{abstract}

\section{INTRODUCTION}

Different definitions of audiovisual materials (AVMs) have been forwarded in the perspective of different scholars worldwide. The definitions relate AVMs as means to teach English speaking skills (ESS). The scholars like Singh (2005) and Thamil (2007) et al., forward and conceptualize AVMs as devices that increase individuals' ESS by sight and sound. As the scholars added, they are instructional aids that are used in the classroom to encourage learning and make it easier and interesting. Besides, they present information through the sense of hearing as in audio resources, sight as in visual resources or through a combination of both. They are commonly referred to as instructional materials that are 
used to convey meaning without complete dependence upon verbal symbols or language (Anzaku, 2011).

In terms of types, there are several of them that boost in and help as the means to teach ESS. Some of them that typically known and used in teaching ESS are: filmstrips, tape recorders, cartoons, flipcharts, LCD projectors, video compact discs, multimedia, radios, maps, graphs, models, posters, pictures and flashcards.

Regards the advantage, different scholars state out their own views as AVMs boost in teaching learning activities of the classroom. According to Eze, (2013) when the teachers use these materials to teach ESS, they make teaching and learning process more easy, convenient and faster. Besides, Meshesha and Amanuel, (2018), stated out that these aids make learning process more effective and conceptual. They are the means through which teachers grab the attention of their students. Besides, they make teaching and learning process more practical, interesting and live. When the teachers use AVMs effectively, they enhance the energy level of teaching, free overburdened classrooms and provide the students a realistic approach. Meanwhile, the culture and climatic conditions of the other countries can be brought into the classroom with the aid of these materials. When the teachers plan, construct and use them effectively, they enhance the classroom's atmosphere and ensure greater participation of the learners (Umar, 2014).

However, there are perceived factors that drawback teachers' effective use of AVMs to teach ESS. These factors can negatively affect the teachers' use of AVMs while the teachers teach ESS. The statement can be supported by Ismail, (2006) that the main factors hinder teachers' effective use of AVMs to teach ESS are:

technical challenges, time constraint, the size of the classrooms, misconception of students, sound and vision of AVMs. Another important issue in this case is technical skills of teachers to maneuver these materials; the teachers should be well trained on using and exploiting the gadget.

Technically, there are many things that would go wrong and may derail back teachers' effective use of AVMs while teaching ESS. Each kind of teaching materials requires a special treatment and ways of dealing with. When using a power-point presentation, font and colors may show up differently on screen or the music and sound might not play synchronously; CDs can skip and DVDs may be scratched (Yousra, 2013). Besides, a bulb might be burnt out on the projector or it might be blurry or hard to focus.

The time has also its own impact on teachers' effective use of AVMs to teach ESS. It plays an important role on both preparation and presentations of them. Time is needed to produce your own video or slides if you want to do so. Posters and transparencies may require extensive preparation. Creating a power point presentation can also be time consuming. Due to time consumption, teachers may face constraint to use AVMs (Anubha, 2015 and Deepa, 2014).

When audiovisual aids are preferred to be used, the size of the classroom should be taken into a great consideration. Unless it is properly managed, the size of the classrooms creates negative impact on teachers' effective use of AVMs to teach ESS. The reason is that all students are able to watch or listen the presentation in a single classroom. If the room is too large for everyone to watch the visual aids, or if parts of audiences are forced to view the presentation at odd angles, it will struggle some students to keep up with the lesson and these results in a barrier upon the teachers' use of AVMs (Singh, 2005).

Misconception of students on teaching aids also brings negative impact on teachers' effectiveness to teach ESS. Some of the students may have less consideration on the use of AVMs especially to teach ESS. Thus, they may play hooky, come late or disturb in the 
classroom while teaching and learning process carryon. As a result, these learners' demotivation and loss of interest put the teachers into stress (Gordon, 2007).

Whereas, in terms of the targeted schools' context, English teachers seem do not effectively use AVMs to teach ESS. They come across the challenges to use AVMs; however, these materials benefit the students in enhancing realistic approach. The following were the perceived drawbacks those impede the targeted teachers' effective use of AVMs to teach ESS. Such as teachers' technical challenges to maneuver the gadget, class size, time management and misconception of students towards the utilization of the aids. Therefore the researcher of the current study was inspired to conduct the study in order to extract out the drawbacks hinder teachers' effective use of AVMs to teach ESS at the targeted venue.

So many researches that have been conducted on the utilization of AVMs to teach English language skills: reading, writing, speaking and listening skills considering tutors' and learners' perception and practice on its usage. Thus, the following research works have proximity to the purpose and theme of this manuscript. Among so many of them, Nalliveettil and Ali, (2013), focused on the usefulness of AVMs in EFL classroom: implication for effective instruction. Then, the findings indicated, EFL textbooks with technological aids often viewed to be an inspiration and provide motivation in classroom instruction.

Similarly, Jemima, (2013), conducted a general study on audiovisual aids in teaching of English. The researcher's data indicated that, though audiovisual aids help the students in verbalization, most of the teachers do not use the aids. Still, Mehmet \& Sule, (2016), focused on the challenges of using audiovisual aids as warm-up activity in teaching aviation English. According to the analyzed result, the challenges encountered in the use of video are concluded to arise from curriculum design, technical constraints and video selection.

Besides, Alabere, (2017), conducted on the importance of instructional materials in teaching English as a second language. Then, the data indicated the performance of the targeted secondary school students who were taught without the use of teaching materials was very poor. Furthermore, Meshesha and Amanuel, (2018), conducted the research on teachers' perception on the use of audiovisual materials to teach English speaking skill: Abba Pascal Girls' school in focus. The researchers' results indicated that all English language teachers of grades 5, 6, 7 and 8 at Abba Pascal Girls' School have positive perception on the use of audiovisual materials to teach English speaking skills.

Therefore, the current study is not only different in scopes and themes from the above mentioned research works that have been conducted by different scholars. So, what makes it different from the above mentioned is its only focus on teachers' effective use of AVMs to teach ESS. Besides, it is neither a comparative study nor investigates into perception and practice of students in terms of using AVMs. Still it neither focuses on some other languages, English media subjects and the subjects' teachers. However, the current manuscript's main focus is only on English language and the language subject teachers. Besides, it is not a separate piece of work that focuses only on audio or video; however, it concurrently studies both audiovisual materials. Therefore, in terms of the above mentioned barriers and occurred research gaps, the researcher motivated to conduct the current study on the factors hinder teachers' effective use of AVMs to teach ESS at Abba Pascal Girls' School; Wolaita Zone, Ethiopia. 


\section{RESEARCH METHODS}

\section{Research Design}

The researcher used descriptive research design to describe the facts and characteristics of a given population factually and accurately. Then, he described factors hinder teachers' effective use of AVMs to teach ESS using the design. The data were collected via students' questionnaire, teachers' interview and classroom observation of grades 5, 6, $7 \& 8$ at Abba Pascal Girls' School. Afterwards, the results were analyzed in both quantitative and qualitative approaches of data analysis. The former was employed for close-ended questionnaires and structured interviews; the later qualitative was employed for classroom observation, semi-structured interviews and open ended questionnaire.

\section{Setting of the Study}

The research was conducted at Abba Pascal Girls' School, which is found in Wolaita Sodo town in Wolaita Zone, South Nations, Nationalities and Peoples' Regional State (SNNPRS) of Ethiopia. The school was consisted of 2 English language teachers at the level of grades 5, 6, $7 \& 8$ in the year 2019 G.C. Hence, the targeted school was selected as a research setting due to its convenience and awareness of the research problem under the study.

\section{Participants of the Study}

The participants of this study were the selected students and both English language teachers of grades 5, 6, $7 \& 8$ at Abba Pascal Girls' School. The total number of population was 402. Among them 400 were students and the rest 2 were English language teachers who were teaching at the catchment areas of the study. The targeted grades consisted of two sections each and the sections encompassed 50 students. Totally, there were 8 sections of the targeted grades in the year 2019 G.C. Therefore, the reason for the selection of the participants was they were assumed to provide tangible and accurate data for the research due to their direct contact to AVMs.

\section{Sampling Technique}

Convenience and systematic sampling techniques were employed to select the targeted school and informants among students' population. This created an opportunity to select the school proximally. Meanwhile, grades of the school that consisted of 2 sections encompassed 50 students each. In this regard, the total number of student population is 400 $(50 * 8=400)$. Systematic sampling technique was employed to select $32(8 \%)$ participants among the total population. So, every $\mathrm{N}^{\text {th }}$ participants were selected systematically according to their attendance lists of the classrooms. The informants of the sections represent 12 students each. To do this, the researcher divided the population of each section into the numbers of each student's representation as follows: $50 \div 4=12.5$. Then, 4 informants from each section and totally, 32 respondents were taken as informants of the study due to intention of the researcher. On the other hand, 2 of the English language teachers of the catchment area were comprehensibly taken as informants of the study due to their manageable number of the entire population.

\section{Tools of Data Collectiont}

To gather valid and accurate data from the respondents, the researcher used questionnaire, interview and classroom observation as the instruments of data collection. 


\section{Data Analysis}

The researcher analyzed and interpreted the collected data by using mixed approach of data analysis. This approach was used to analyze the data that the researcher collected via the questionnaire, interview and classroom observation with the prepared checklist by the researcher. Then, the researcher analyzed the quantitative data using percentage and qualitative date in a form of statement. Finally, he put the data thematically in merging and triangulating similar results together.

\section{RESULTS AND DISCUSSION}

This chapter presents analysis of the data gathered through the instruments, elicits main finding of the study and finally discusses the study. Thus, after collecting the data via the tools, the researcher organized and analyzed them using percentages and in a statement form based on the challenges drawback teachers' effective use of AVMs to teach ESS.

\section{Analysis of Students' Questionnaire}

The Responses of students on the factors that hinder teachers' effective use of AVMs to teach ESS.

Table 1. Challenges drawback teachers' effective use of AVMs while they teach ESS

\begin{tabular}{|c|c|c|c|c|c|c|c|c|c|c|c|c|c|}
\hline & \multirow[t]{2}{*}{ Items } & \multicolumn{2}{|c|}{$\begin{array}{l}\text { Strongly } \\
\text { agree }\end{array}$} & \multicolumn{2}{|c|}{ Agree } & \multicolumn{2}{|c|}{ Neutral } & \multicolumn{2}{|c|}{ Disagree } & \multicolumn{2}{|c|}{$\begin{array}{l}\text { Strongly } \\
\text { Disagree }\end{array}$} & \multicolumn{2}{|c|}{ Total } \\
\hline & & Freq & $\%$ & Frec & $\%$ & Freq & $\%$ & Freq & $\%$ & Freq & $\%$ & Freq & $\%$ \\
\hline 1 & $\begin{array}{l}\text { Do you agree that learning ESS with } \\
\text { the help of AVMs is beneficiary? }\end{array}$ & 24 & 75 & 6 & 18.76 & 2 & 6.26 & 0 & 0 & 0 & 0 & 32 & 100 \\
\hline 2 & $\begin{array}{l}\text { Do you agree in the presence of factors } \\
\text { hinder the effective use of AVMs while } \\
\text { your teachers teach ESS? }\end{array}$ & 26 & 81.2 & 4 & 12.5 & 0 & 0 & 2 & 6.26 & 0 & 0 & 32 & 100 \\
\hline 3 & $\begin{array}{l}\text { Do you agree that your class size is } \\
\text { comfortable to learn the skills using } \\
\text { AVMs? }\end{array}$ & 0 & 0 & 0 & 0 & 0 & 0 & 6 & 18.76 & 26 & 81.2 & 32 & 100 \\
\hline & & Very & good & Good & & Fair & & Poor & & $\begin{array}{l}\text { Very } \\
\text { poor }\end{array}$ & & Total & \\
\hline 4 & $\begin{array}{l}\text { How far do your English teachers } \\
\text { skilled to maneuver AVMs? }\end{array}$ & 2 & 6.26 & 6 & 18.76 & 24 & 75 & 0 & 0 & 0 & 0 & 32 & 100 \\
\hline 5 & $\begin{array}{l}\text { How is the sound and vision of AVMs } \\
\text { while your teachers use them? }\end{array}$ & 0 & 0 & 6 & 18.76 & 23 & 71.87 & 3 & 9.37 & 0 & 0 & 32 & 100 \\
\hline 6 & $\begin{array}{l}\text { How is the time management of your } \\
\text { teachers while they use AVMs to teach } \\
\text { ESS? }\end{array}$ & 0 & 0 & 4 & 12.5 & 23 & 71.8 & 5 & 15.6 & 0 & 0 & 32 & 100 \\
\hline
\end{tabular}

In response to item one, $24(75 \%)$ the highest number of the respondents strongly agreed that learning speaking skills with the help of AVMs is beneficiary. The informants those who strongly agreed, provided their point of views as follows:

Audiovisual materials make learning more practical, stimulate interest in a realistic approach and let scoop up the attention of students. Besides, they create opportunity to adopt technology in the classroom and acquire the exact pronunciation of native speakers. 
Meanwhile, $6(18.76 \%)$ of the respondents agreed on the provided statement. Whereas, $2(6.26 \%)$ of them were neutral for the question. Conversely, neither of the respondents disagreed and strongly disagreed. The above data implies that the students are benefited when they learn ESS with the help of AVMs. Because, these aids make teaching and learning process more, practical, realistic, interesting and live (Umar, 2014).

Besides, in the same table item two, highest number of the respondents $26(81.2 \%)$ strongly agreed in one accordance that there were challenges hindered their English teachers' effective use of AVMs. As the respondents stated out,

fear of technology, sound and vision of AVMs, time constraint to prepare and adjust the materials, teachers' technical challenges, the size of the classrooms and misconception towards the use AVMs brings negative impact on teachers use of AVMs to teach ESS.

Meanwhile, the rest $4(12.5 \%)$ of the respondents agreed that there were factors drawback their teachers effective use of AVMs to teach ESS. On the contrary, only 2 $(6.26 \%)$ of the respondents have disagreed on the provided statement. Neither of the respondents preferred neutral and strongly disagreed. Therefore, the researcher deduced that teachers' effective use of AVMs to teach ESS is in a challenge. These views can also be supported by Yousra (2013) and Deepa, (2014) that technical challenges, unmanaged time, size of the classrooms, and misconception of the students towards AVMs negatively affects the effective use of the aids to teach ESS.

On the other hand, in item three for question that asks whether the classroom was comfortable to learn ESS using AVMs or not, the highest number 26 (81.2\%) of respondents strongly disagreed in one accordance that the classrooms were not suitable to learn ESS using AVMs. As the respondents who replied so reasoned out, the classrooms echoed when AVMs were being played. Besides, the number of the students which was 50 in each classroom did not create a conducive environment. The rest $6(18.76 \%)$ of the respondents disagreed on the suitability of their classrooms. Meanwhile, neither of them was neutral, strongly agreed and agreed on the provided statement respectively. Therefore, as the data indicated, the class size was not comfortable to teach ESS. This view is supported by Singh, (2005) who points out that, when the room is too large for everyone to watch the visual aids, or if parts of audiences are forced to view the presentation at odd angles, it struggles some students to keep up with.

In the same table item four, only $2(6.26 \%)$ informants replied that the severity of English teachers' skills to maneuver AVMs was very good. Whereas, among the rest 6 $(18.76 \%)$ of the respondents assured that the teachers' capability was good. Conversely, the highest number, 24 (75\%) of the respondents replied that the skill of teachers was fair to maneuver AVMs. Meanwhile, none of them preferred poor and very poor. The above data indicates that the targeted teachers of the school were fairly skilled enough to maneuver AVMs while teaching ESS. As the respondents stated out their view, the teachers need a special training and earn skills to maneuver AVMs. This lack of expertise brings negative impact on teachers' effectiveness to use AVM. This view is supported by Umar (2014), that teachers' skills to maneuver teaching aids enhance in effective teachinglearning process.

Whereas in item five, $6(18.76 \%)$ of the respondents replied that the quality of sound and vision of AVMs was good. Only $3(9.37 \%)$ of them ticked on poor. However, almost the highest number of the respondents $23(71.87 \%)$ replied the sound and vision of AVMs was fair to be harken. Neither of them preferred very good and very poor respectively. The respondents, who replied fair, underlined echo as the main barrier on the quality of the sound. On the other hand, the sun-rays reflected into the classrooms through the windows 
were also the other barrier brought impact on the quality of screens' vision. Thus, this can be deduced that the sound and vision of AVMs were fair due to the echo and the sun-rays that reflect through the windows. Alabere, (2017) supports the statement that the position of windows let the sun-rays reflect inside and the size of the classrooms that create echo, bring negative impact on the qualities of sound and vision of AVMs.

In the last, for the question forwarded, whether the teachers manage time well while using AVMs to teach ESS or not, 4 (12.5\%) of the respondents replied that it was good. Whereas, the highest number of the respondents $23(71.8 \%)$ replied it was fair. On the contrary, $5(15.6 \%)$ of the respondents replied poor. Conversely, neither of them preferred for very good and very poor respectively. As a result, teachers' time management while using AVMs to teach ESS was fair due to technical challenges and the time it consumes to be prepared. As Eze, (2013) stated, time is needed to produce video or slides. Posters and transparencies may require extensive preparation. Creating a power point presentation can also be time consuming.

To put the above whole data extracted out of the questionnaire thematically, learning speaking skills with the help of AVMs is beneficiary. Because, these materials make learning more practical, stimulate interest in a realistic approach and let scoop up the attention of students. Besides, the challenges related to AVMs, the challenges related to the teachers, and the challenges related to the students impede teachers' effective use of AVMs to teach ESS.

\section{Analysis of Teachers' Interview}

Teachers' response on the factors impede the effective use of AVMs to teach ESS

The researcher of this study used the tool to triangulate and assure validity of the data as rest of the tools. In this case, 2 of the English language teachers of the targeted institution were asked semi-structured interviews. The interviews were thematically consisted of challenges related to the use of AVMs, challenges related to the teachers, challenges related to the classrooms and challenges related to the students. Therefore, the researcher put statements of the respondents accordingly: for the interview question forwarded on the benefits of AVMs, the respondents stated that these aids benefit both the teachers and students. As they added,

however it consumes time to be prepared and adjusted, when well-managed they let teachers transfer whole ideas in a single screen and adopt the technologies of developed countries in the classroom. Besides, they make learning more practical; stimulate the students' interest in a realistic approach.

Likewise, for the interview question forwarded whether there were challenges that hamper their effective use of AVMs while they teach ESS or not, both of the respondents assured the presence of challenges. As they stated out,

sound and vision of AVMs, their time consumption to be prepared and adjusted, technical challenges, size of the classroom, the number of students and the position of the windows bring negative impact on our effective use of AVMs while we teach ESS.

As the respondents stated out, class size and students' number which is 50, did not give them comfort to teach speaking lessons especially using AVMs. Because, the classrooms echoed during practical sessions; the number of students was not comfortable to practice speaking activities. Still, the respondents were not skilled enough to maneuver AVMs due to newness of technology and lack of training. However, they coped up such the challenges by the assistance of technicians in need. 
There were also indicated barriers related with sound and vision of AVMs. As they stated, the echoes created due to classes' size and sun-rays reflect through the windows had negative impact on clarity of sound and vision of AVMs. As the data indicated, these materials consumed time to be prepared and adjusted in the classrooms.

\section{Analysis of Classroom Observation \\ Results of classroom observation}

Classroom observation was taken place for 16 periods of grades 5, 6, 7 and 8 . That is each grade's sections of speaking periods were intentionally observed twice to assure accuracy of the data depending on the observation checklist format prepared by the researcher. The researcher then, observed every activities and the real situations of the classrooms being there. Typically, teachers' and students' activities of the classrooms, situation of the classrooms, the number of students, the comfort of chairs and tables, teachers' time management and their skills to maneuver AVMs were the focal points.

Thus, as the observed data indicated, almost all the students were punctual to the classrooms and showed vital participation when they learn ESS with the help of AVMs. On the other hand, due to echoes of the classrooms' and sun-rays that reflected through the windows there were challenges on clarity of vision and sound of AVMs while ESS sessions carry on. Similarly, the number of students, chairs and tables of the classrooms did not do for speaking sessions. Finally, selecting, preparing and adjusting AVMs to teach ESS consumed the teachers precious time due to their incapability to maneuver them.

In conclusion, as the thematic data extracted from the tools indicated, learning ESS with the help of AVMs benefits both the teachers and students in many ways. They make learning and teaching more practical; stimulate interest in a realistic approach and let scoop up the attention of the learners. Besides, they create opportunity to adopt technology to classroom and acquire the exact pronunciation of native speakers. In terms of challenges, the fear of technology, sound and vision of the materials, time constraint, teachers' technical challenges, the size of the classrooms that echo and the excess number of students that creates discomfort to manage and the sun-rays reflect through the windows create impact on teachers' effective use of AVMs to teach ESS.

\section{CONCLUSION}

The results of analysis indicated that learning ESS with the help of AVMs benefits both the teachers and the students. Because, they make learning and teaching more practical; stimulate interest in a realistic approach and let scoop up the attention of the learners. They also create opportunity to adopt technology to classroom and acquire the exact pronunciation of native speakers. The findings also implied that there are challenges impede teachers' effective use of AVMs to teach ESS. These challenges are underpinned in the following categories: the challenges related to the classroom, challenges related to the gadgets, challenges related to the teachers and the students.

The following conclusions have been drawn from all analyzed results above.

* Learning ESS with the help of AVMs makes learning more practical, stimulates interest, creates opportunity to adopt technology in the classrooms, assists lively listen to the exact pronunciation of native speakers and let scoop up the attention of students.

* The fear of technology, sound and vision of AVMs, time constraint, teachers' technical challenges, the size of the classroom and misconception towards AVMs brought negative impact on teachers' effective use of AVMs to teach ESS.

* The classrooms created discomfort to teach ESS using AVMs due to the number of students, the space that echoes and the sun-rays reflect through the windows. 
* Due to lack of training and newly arrived technology, the teachers were fairly skilled to maneuver AVMs while teaching ESS.

* Sound and vision of the screen of the aids was fairly observable and harken due to the echoes of the class and the sun-rays reflect through the windows.

* Teachers' time management was fair due to technical challenges and the aids' time consumption to be prepared.

\section{Recommendations}

Based on the findings and conclusions, the following recommendations have been forwarded.

* The stakeholders of the institution should adjust the training sessions for English teachers on how to maneuver AVMs.

* The teachers should equalize or adjust the sound and color of AVMs while teaching ESS in order to minimize the barriers.

* The windows of the classrooms should be painted with non-translucent paint or use curtains to diverge the sun-rays.

* Power-point slides, movies, CDs, should be given consideration and prepared beforehand.

* The size of the classrooms should be done with the number of students.

* The advices and awareness towards AVMs should be given to students.

\section{ACKNOWLEDGMENT}

The author wish to thank Dr.M.Senapathy, Associate Professor, Department of Rural Development and Agricultural Extension, College of Agriculture, Wolaita Sodo University, Ethiopia for his constant and continuous support, insightful comments and encouragement for this publication process. I have to thank the Teachers and Students of Abba Pascal School, including School Administrators have allowed me to collect the data with fullest cooperation.

\section{REFERENCES}

Alabere Rabiat Ajoke (2017). The importance of instructional materials in teaching English as a second language. Universiti Utara Malaysia/CAILS, IIorin, Nigeria, International Journal of Humanities and Social Science Invention, 6(9), Pp. 36-44.

Anubha Ray and Sanat Kumar Lenka (2015). Authenticity of text and context in reading and speaking. Centurion University of Technology and Management: Ramchandrapur, Jatni, Bhubaneswar 752 050, Odisha. The Criterion: An International Journal in English, 6(2).

Anzaku Francis (2011). Library experts speak on audio-visual material. A paper presented at the UNESCO World Day for Audio-Visual Heritage: Lafia.

Deepa Awasthi (2014). Utilizing audiovisual aids to make learing easy and effective in primary education. University of Laucknow, Uttar Pradesh, India. International Journla of Scientific Research, 3(8), 227-8179.

Eze, E.U. (2013). Effect of instructional materials on the academic performance of junior secondary school students in social studies. Unpublished PGDE Thesis: Imo State University, Nigeria.

Gordon, Tatiana (2007). Teaching young children a second language. Eds. Fromberg, D. P. and Leslie R. Williams: Praeger, London. 
Ismail Cakir (Dr.) (2006). The use of audio as an audiovisual material in foreign language classroom. The Turkish Online Journal of Educational Technology, 5(4), 67.

Jemima Daniel (2013). Audiovisual aids in teaching of English. Chennai-600 03, India. International Journal of Innovative Research in Science, Engineering and Technology, 2(8).

Mehmet Sahin and St. Sule, Y.E. Secer (2016). Challenges of using audiovisual aids as warm-up activity in teaching aviation English. Yildiz Technical University, Turkey. Educational Research and Reviews, 11(8), 860-866.

Meshesha Make and Amanuel Yonas (2018). Teachers' perception on the use of audiovisual materials to reach English speaking skill:Abba Pascal Girls School in focus. Wolaita Sodo and Arba Minch University, Ehtiopia. International Journal of English Language and Literature Studies, 7(1), 1-6.

Nalliveetil George Mathew and Ali Odeh Hammoud Alidmat (2013). A study on the usefulness of audiovisual aids in EFL classroom: Implicaitons for effective instruction. International Journal of Higher Education, 2(2).

Singh, Y.K. (2005). Instructional technology in education. New Delhi:Darya Ganj.

Thamil Selvi. D. R.N.R.M. (2007). Audiovisual aids in education. https://nursingempower.blogspot.com/2007/10/audio-visual-aids-in-education.html Retrieved on $7 / / 8 / / 2015$.

Umar Farooq (2014). Audio visual aids in education, definition, types and objectives. MIER University Press, Egypt.

Yousra Farhi (2013). The significance of Audio Visual Aids in Foreign Language Teaching: The Case of Second Year English Students at Mohamed Khieder University of Biskra, Algeria. 